\title{
Detection and classification of skin cancer using deep learning
}

\author{
Saber Fooladi $^{1}$ (D), Hasan Farsi ${ }^{1}\left[\underline{D}, \underline{\text { Sajad Mohamadzadeh }^{2}}\right.$ \\ ${ }^{1}$ Department of Electrical and Computer Engineering, University of Birjand, Birjand, Iran. \\ ${ }^{2}$ Corresponding Author; Department of Electrical and Computer Engineering, University of Birjand, Birjand, Iran. \\ Tel: +5632202049_E-mail: s.mohamadzadeh@birjand.ac.ir
}

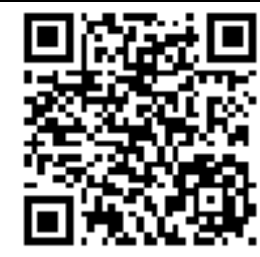

Citation Fooladi S, Farsi H, Mohamadzadeh S. [Detection and Classification of Skin Cancer Using Deep Learning]. J Birjand Univ Med Sci. 2019; 26(1):44-53. [Persian]

DOI http://doi.org/10.32592/JBirjandUnivMedSci.2019.26.1.105

Received: July 8, 2018

Accepted: October 27, 2018

\begin{abstract}
Background and Aim: Skin cancer has grown dramatically over the past decades, and the importance of early treatment is increasing day by day. The purpose of this study is to use deep neural networks to create an auto-diagnosis system for melanoma, in which data is directly controlled as part of a deep learning process.
\end{abstract}

Materials and Methods: In this paper, studies on related pictures of skin cancer were performed. For the diagnosis of benign or malignant skin cancer, the deep neural network classifier is used with the help of the Tensorflow framework and the use of the Keras libraries. The dataset which are used in this study consist 70 images of melanoma and 100 images of benign moles. In the proposed model, $80 \%$ of the database images are used for training and $20 \%$ of the database images are selected for testing.

Results: The proposed method offers a higher detection accuracy than other existing methods, which has increased the accuracy of diagnosis in most cases by more than $10 \%$. The high accuracy of the diagnosis and classification and the speed of convergence to the final result are the characteristics of this Research Compared to other Research.

Conclusion: An automatic system based on deep learning is presented to identify and categorize skin cancer which provides high accuracy and speed.

Key Words: Deep Learning; Skin Cancer; Melanoma; Deep Neural Network 


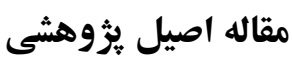

\title{
تشخيص و طبقهبندى سر طان يوست با استفاده از يادكيرى عميق
}

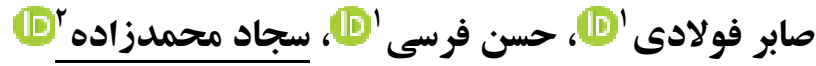

جكيله

زمينه و هدف: سرطان يوست در طول دهلهاى كذنشته رشد حشمَيرى داشته است و اهميت درمان اوليه آن روز به روز در حال

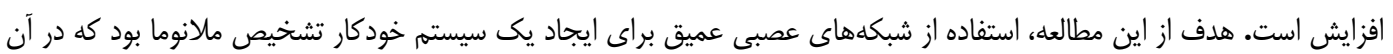

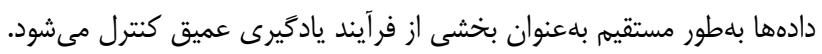

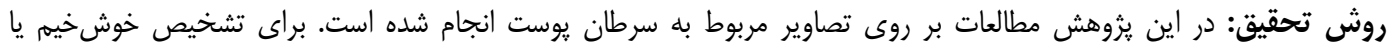

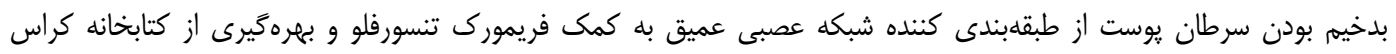

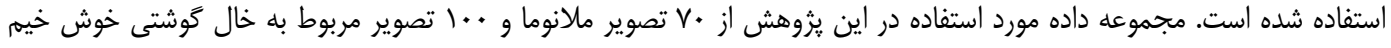

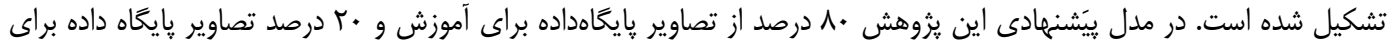

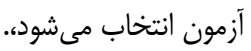

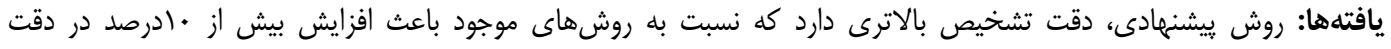

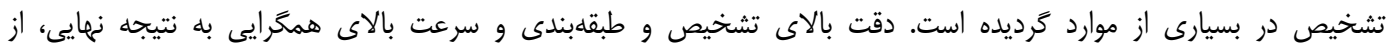

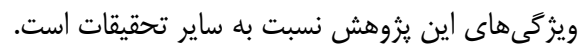
نتيجهَيرى: سيسته اتوماتيك تشخيص و طبقابندى سرطان يوست بر مبناى يادكيرى عميق، با دقت و سرعت مطلوبى ارائه مى شود. وازههاى كليدى: يادَّيرى عميق؛ سرطان يوست؛ ملانوما؛ شبكه عصبى عميق

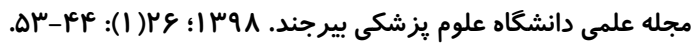
دريافت: 
توسط متخصصان يوست ع VD-AY درصد مىباشد. با اين حال

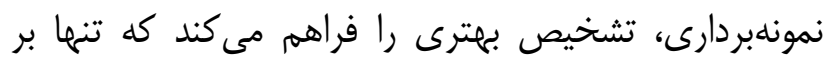

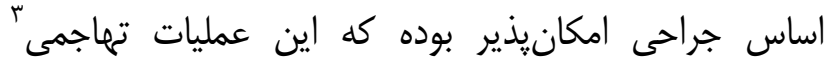

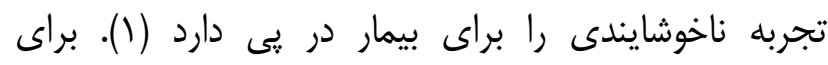

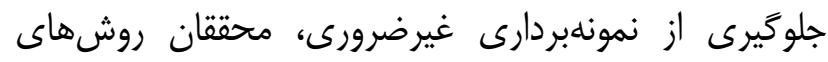

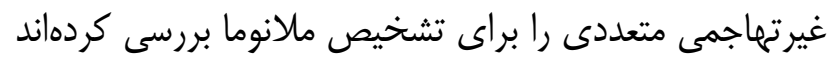

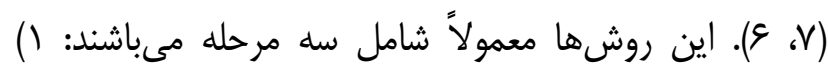

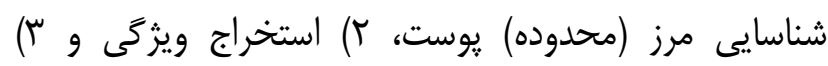
طبقهبندى. فرآيند تشخيص مرز، تومور را در تصاوير مربوط بهابه يوست تشخيص مىدهد كه براى طبقهبندى دقيق ضايعات

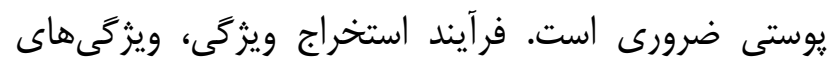

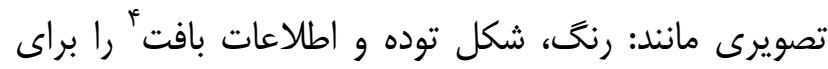

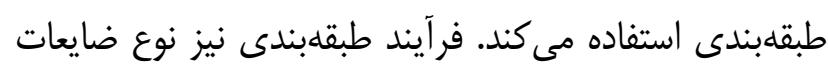

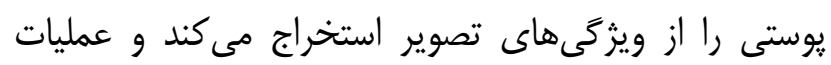
طبقهبندى را انجام مى دهد كه بعضى از اين نوع طبقلهبندى إنها

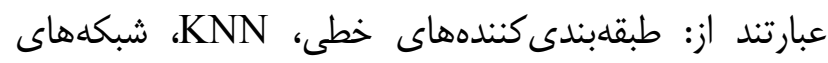

عصبى مصنوعى. ساختار اين مقاله به اين شرح است كه در بخش دوم،

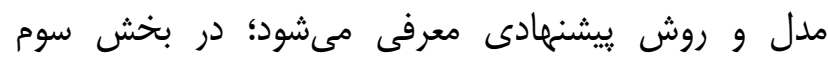

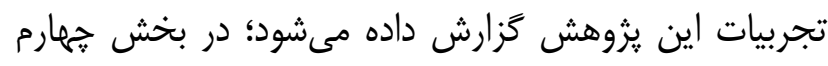

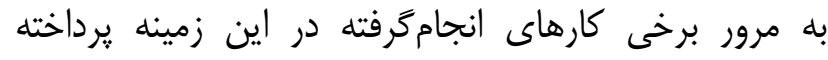

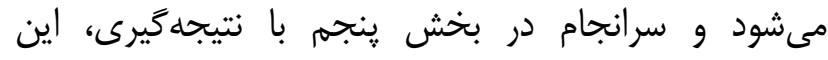
يزوهش به يايان مىرسد.

\section{روش تحقيق}

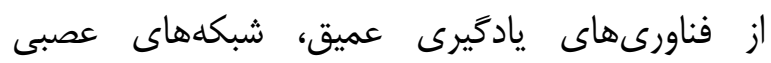

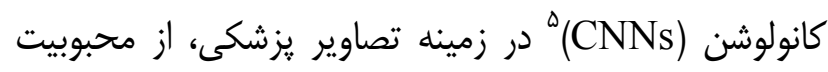

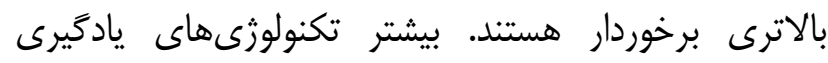

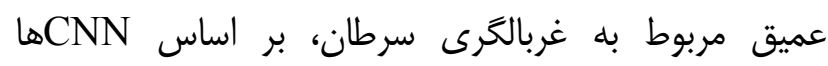
مىباشند. بهكارگيرى شبكههاى عصبى كانولوشن از اواخر

\footnotetext{
${ }^{3}$ Traumatic

${ }^{4}$ Histology

5 Convolutional Neural Networks
}

سرطان يوست در طول دهلهاى گذشته رشد خشمَيرى

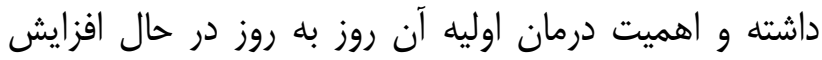

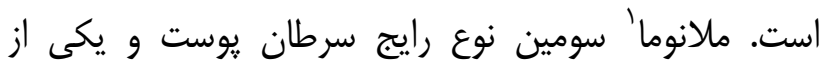

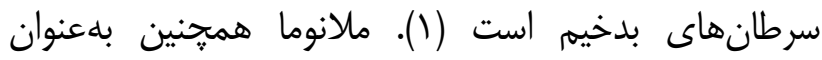

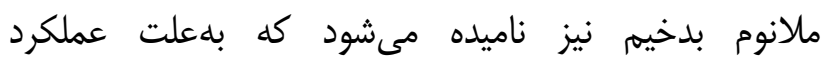

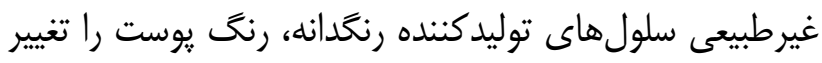

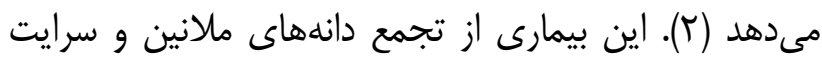

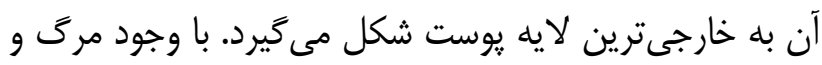

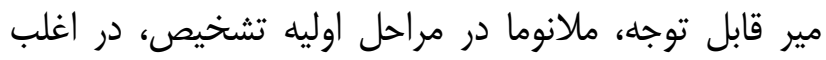
موارد قابل درمان است (ॅ). در همين حال تمايز بين ملانوما

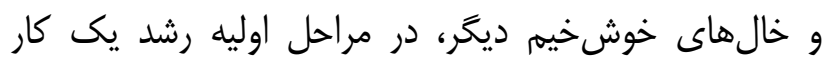
جالشبرانكيز حتى براى متخصصان يوستى است (1) (1).

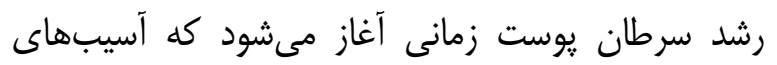

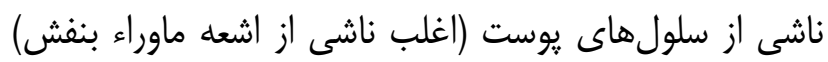

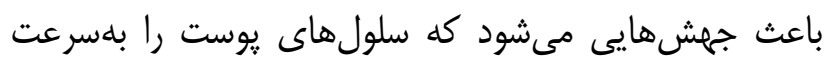

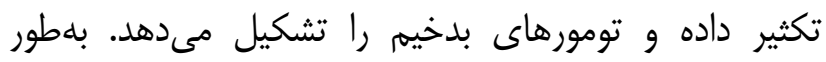

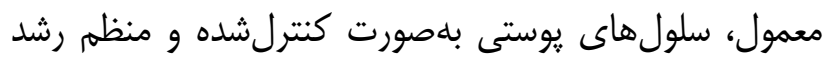
مى كنند؛ اما برخى از سلولهاى تازه تولى توليدشده ممكن است

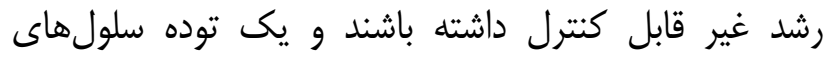

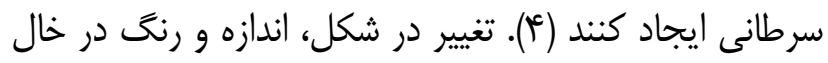

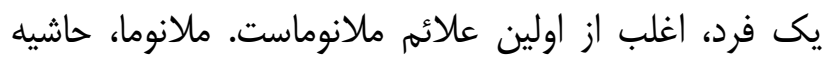

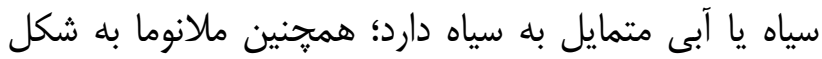

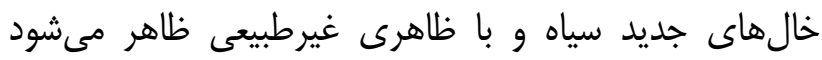

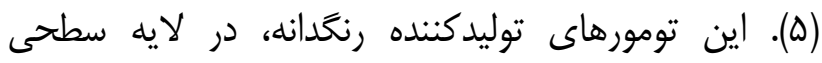
يوست (إيبدرم) آمجود دارند (1). تشخيص سرطان يوست بلهدليل ظاهر انواع مختلف ضايعات يوستى بهخصوص Melanoma و Nevi براى تمايز

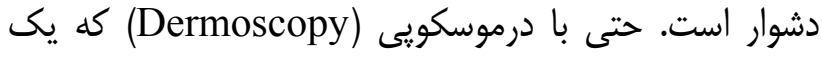
تكنيك آزمايشى غير تهاجمى است، دقت تشخئ درمسيص ملانوم

\footnotetext{
${ }^{1}$ Melanoma

${ }^{2}$ Epidermis
} 
بالا، اثرات نويزى مخرّب بر روى تصاوير را در يى دارد كه با

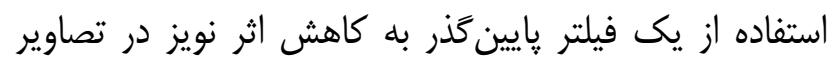

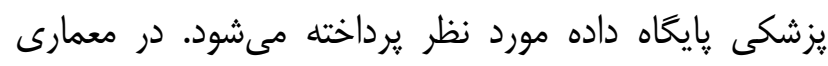

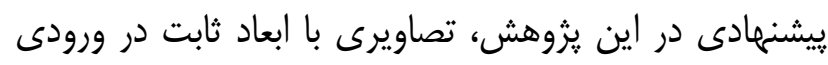

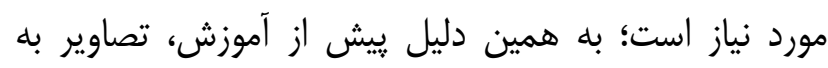

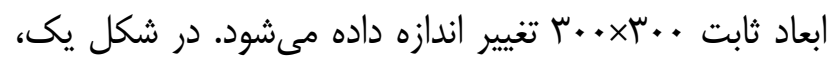

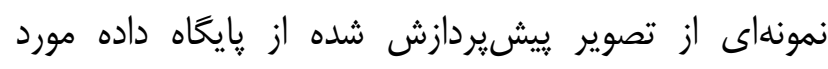

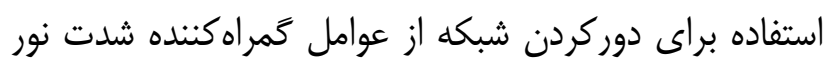
و اثرات نويز، نشان داده شده است.

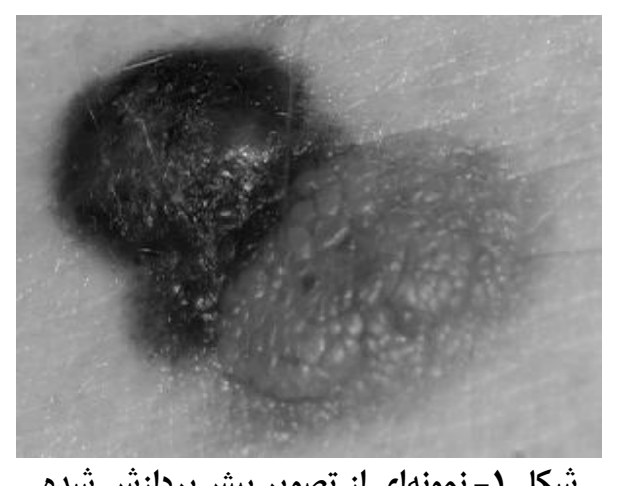

شكل ا - نمونهاى از تصوير يِيشيردازش شده

آموزش شبكه در واقع حداقلكردن تابع خطا بر حسب

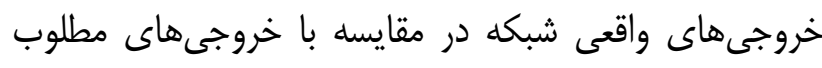

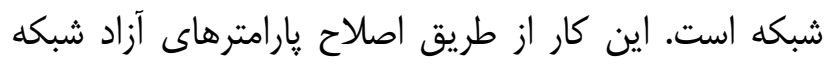

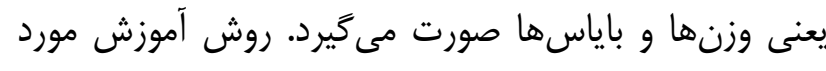

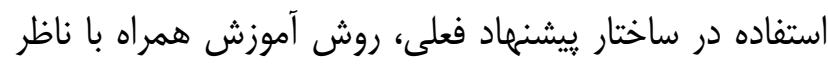

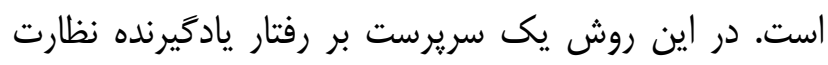

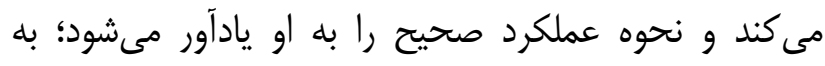

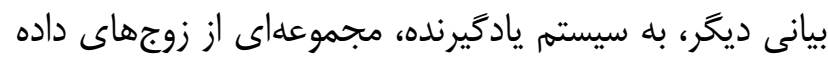

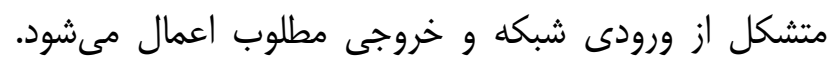

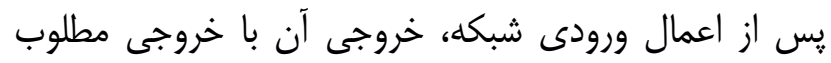
مقايسه شده و سيس خطاى يادگيرى محاسبه و از از آن براى

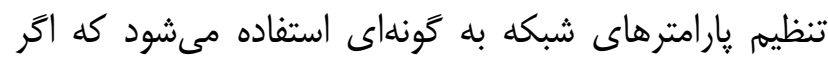

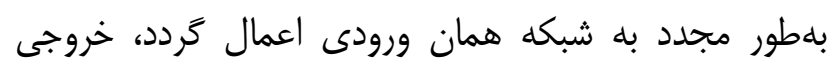

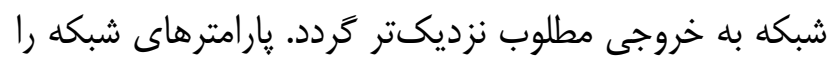

دهه •19V آغاز شده و از سال 1990 به تجزيه و تحليل

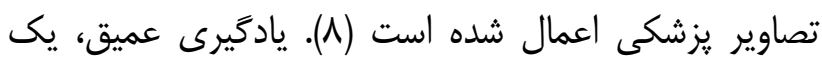

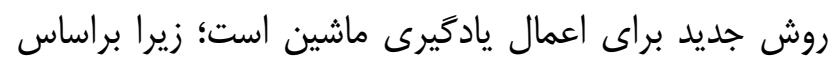

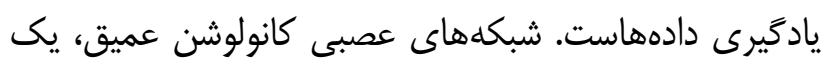
نوع روش يادگيرى عميق مىباشند كه در آن فيلترها قابل تعويض هستند و عمليات ادغام بر روى تصاوير ورودى اعمال

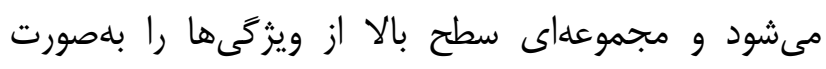

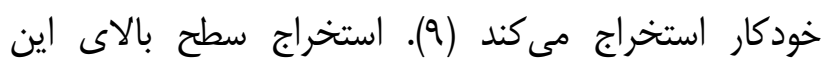

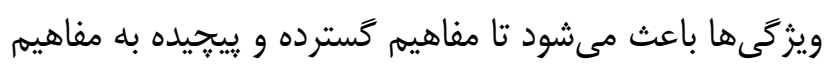

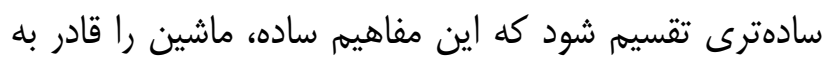

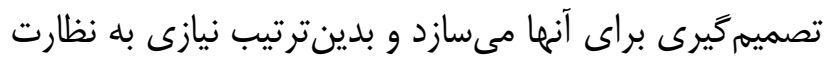

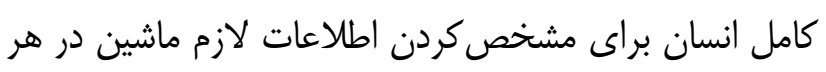

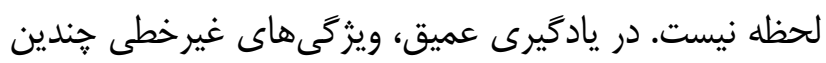

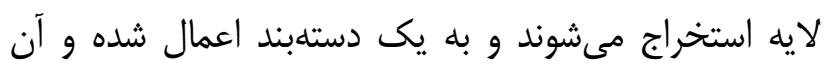

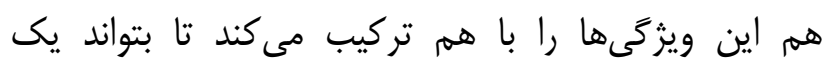
ييشبينى انجام دهد. در اين يزوهش، مطالعات بر روى تصاوير سرطان دهد يوست

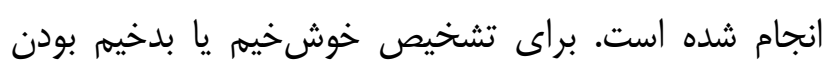

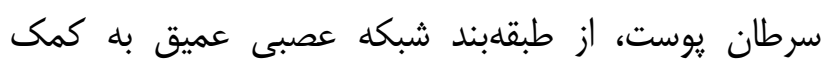

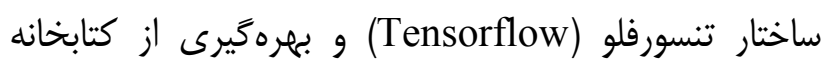

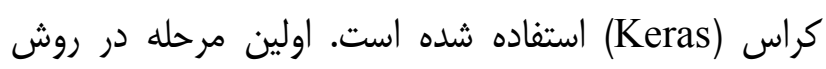

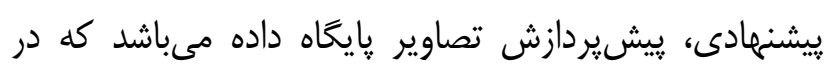

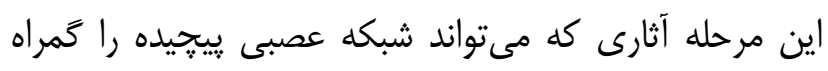

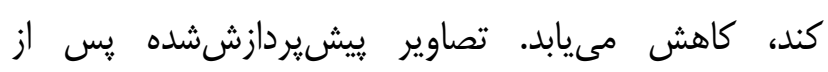

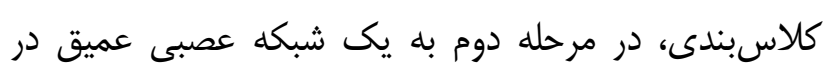

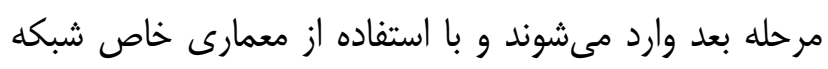

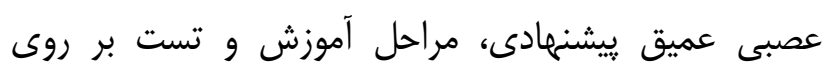
تصاوير اعمال مى

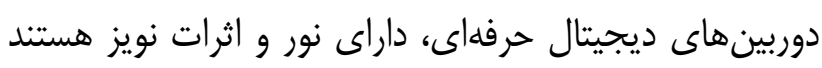

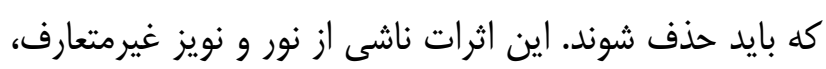

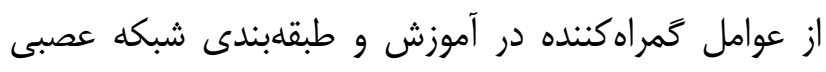
عميق بر روى تصاوير ورودى است. بيكسلهاى با فركانس 
كانولوشن، يك عمليات رياضى براى يردازش سيخنال

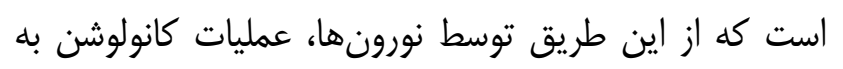

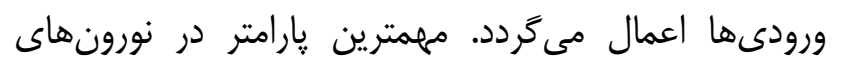

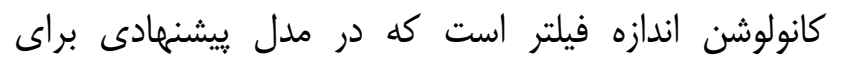
طبقابندى سرطان يوست، از سه لايه كانولوشن با ابعاد فيلتر

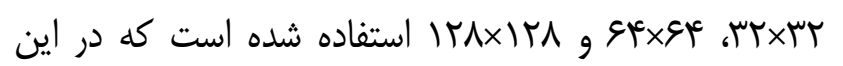

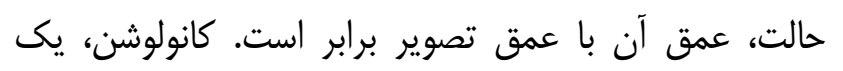

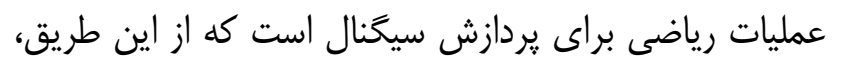

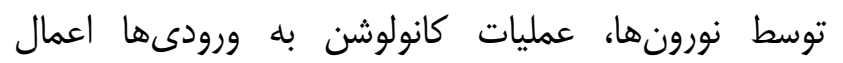

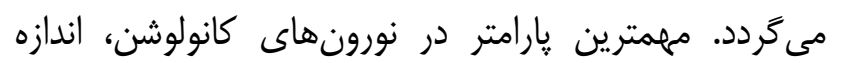
فيلتر مىباشد. بعد از لايه كانولوشن بردئ دار كاهش نورن اندازه فضايى (فقط عرض و ارتفاع نه عمق) از لايه ادغام استفاده

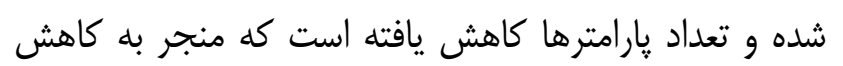

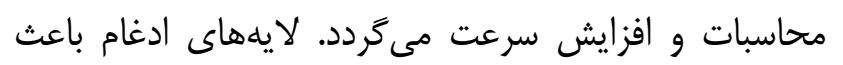
كاهش نمونههاى خروجى فيلتر مىشوند. در اين يزوهش از از

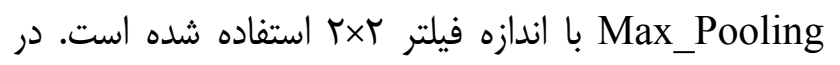
واقع هدف اصلى اين لايه Subsample تصوير ورودى فيلتره بلمنظور كاهش بار محاسباتى، حافظه و تعداد يارامترهاست.
مىتوان به دو طريق آموزش داد: آموزش يس از هر نمونه

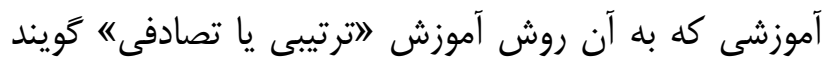

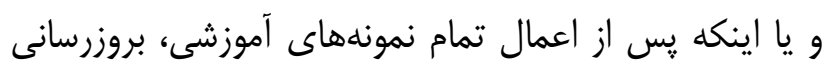

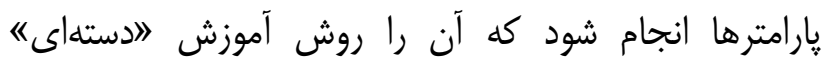

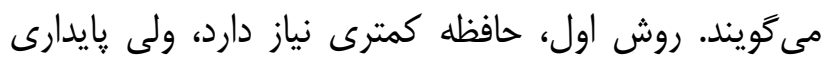

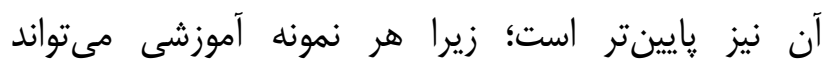

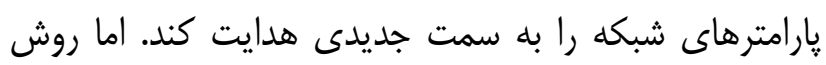

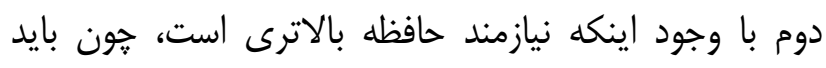

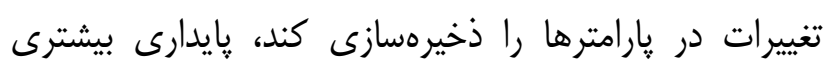

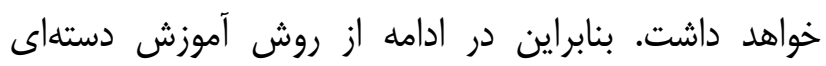

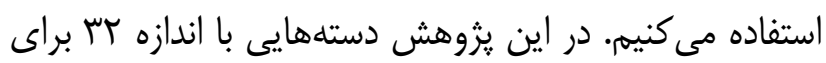
آموزش تصاوير يايخاه داده مورد استفاده قرار گرفته است. در معمارى شبكه عصبى عميق اين يزوهش، از سه لايه كانولوشن و سه لايه ادغام ماكزيمم (Max_pooling) استفاده شده است كه در شكل r شماى كلى ائل اين معمارى نمايش داده شده است. لايه كانولوشن، هسته اصلى

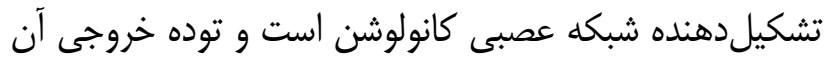
را مىتوان بلهصورت يك توده سلبعدى از نورونها تفسير

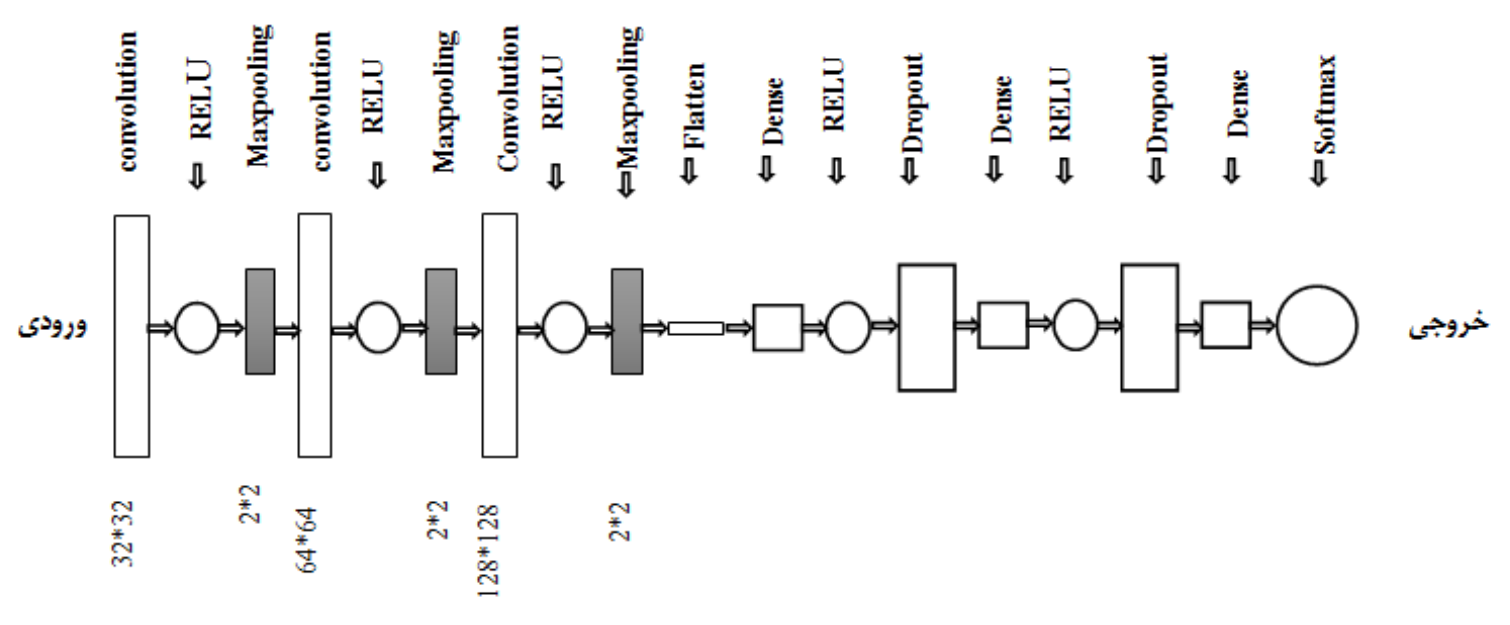

شكل T - مدل يِيشنهادى بر يايه شبكه عصبى عميق 
با استفاده از لايه Dropout در حين آموزش، بر اساس

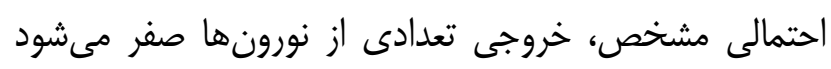

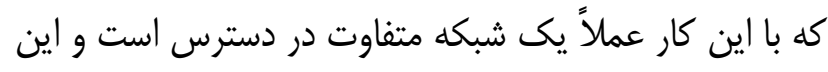

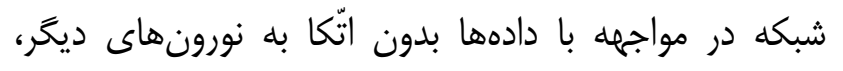
ويزگى هاى قدرتمندى را كشف و استفاده مى كند. بنابراين از

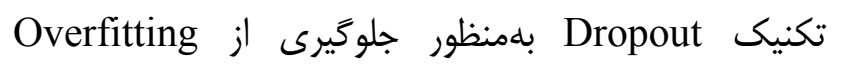
استفاده مىشود. از آنجايى كه در يك شبكانه عميق، تعداد

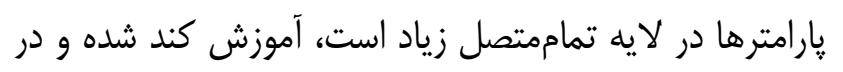

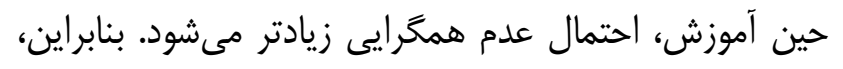

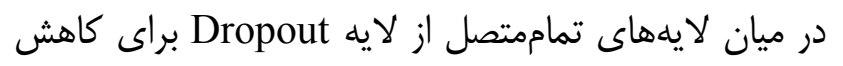

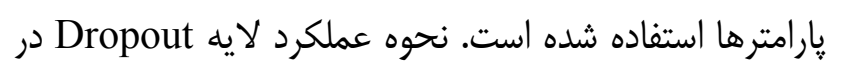
شكل ع آورده شده است.

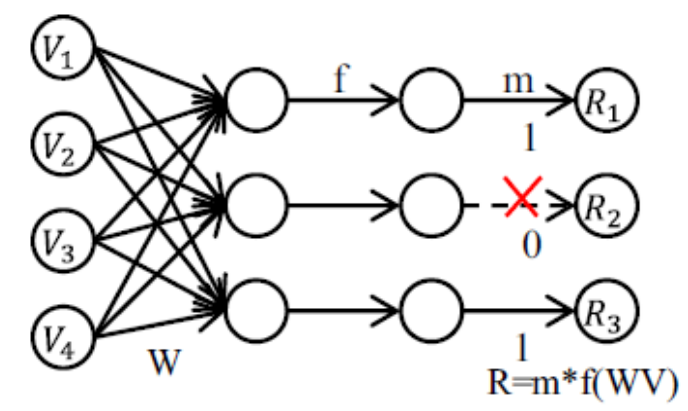

شكل f - نحوه عملكرد لايه Dropout ( ) (1)

يس إز لايه كانولوشن و ادغام، تعداد زيادى صفحات ويثگى إنى

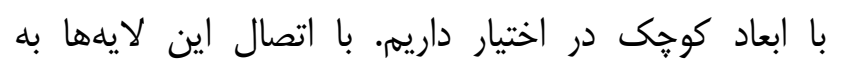

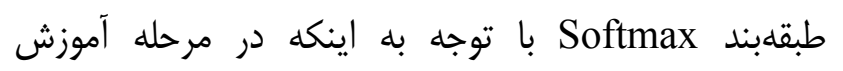
برجهب تصاوير ورودى مشخص است، شبكه مى تونواند با

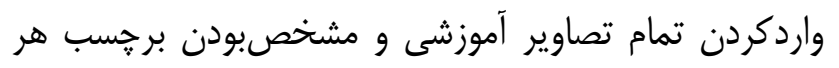

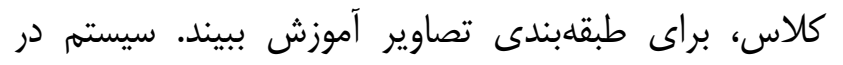

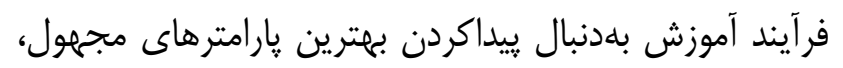

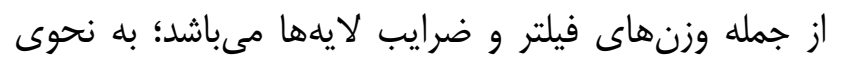
كه كمترين ميزان خطا در طبقلهبندى حاصل شود.
كاهش اندازه تصوير ورودى همجنين باعث كاهش حساسيت شبكه عصبى مىشود. در لايه ادغام مانند لايه كانولوشن، هر نورون به خروجى تعداد محدودى از نورونها

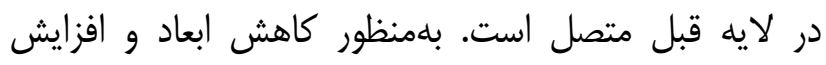
سرعت محاسبات، از لايه ادغام بلمنظور نمونهبردارى استفاده

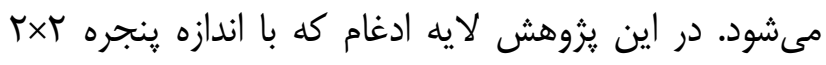

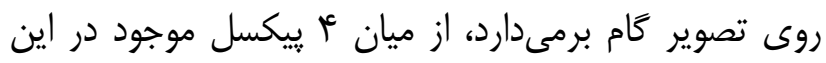

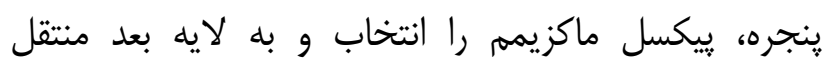

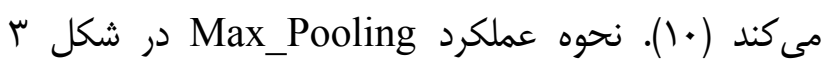
مشاهده مىشود.

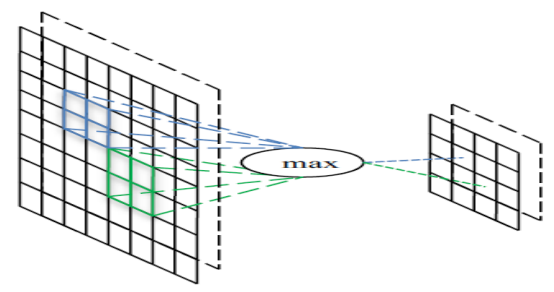

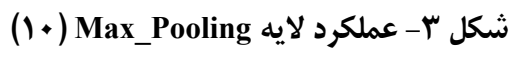

بعد از هر لايه كانولوشن بلافاصله از يك لايه فعال سازى استفاده شده است كه هدف آن معرفى عمليات غير خطى بل بله

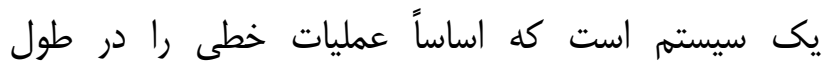

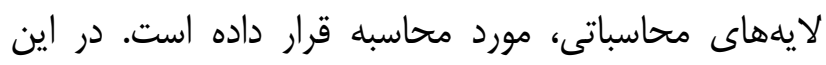
يثوهش از لايههاى RELU استفاده شده است؛ زيرا شبكه

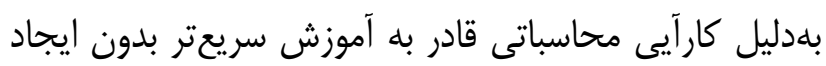

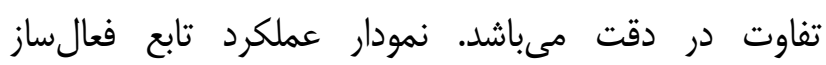

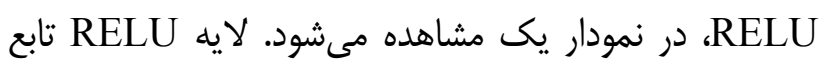

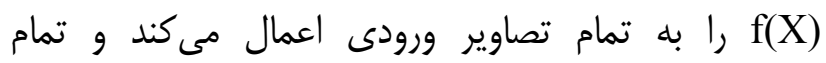

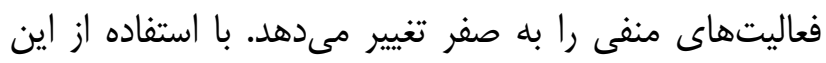

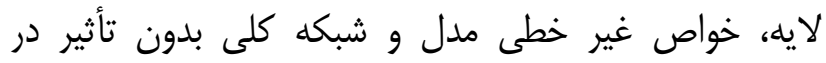
لايههاى كانولوشن افزايش داده شده است.

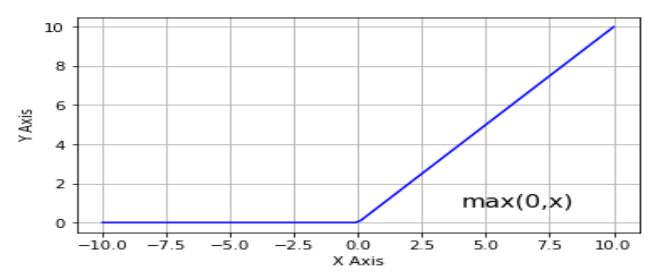

نمودار (- نمودار عملكرد تابع فعالساز RELU (+ (1. ) 
تنظيم شده است (سا). شكل ه نمونهاى از تصاوير קايخاه داده مربوط به كلاسهاى مختلف را نشان مىدهد.

(ب)

(الف)

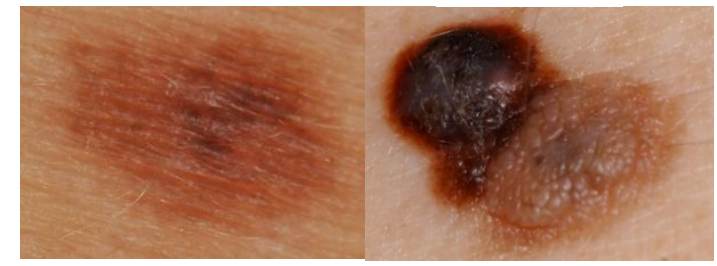

شكل ه- (الف) تصاوير سرطان بوست بدخيم (ملانوما) و (ب)

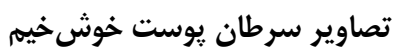

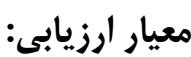
معيار دقّت، معيار سنجشى است كه ميزان توانايى يكى مئى

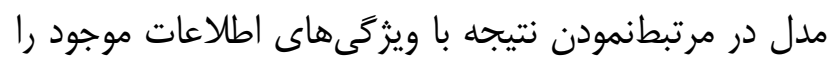
مشخص مىنمايد.

\begin{tabular}{|c|c|c|}
\hline \multicolumn{3}{|c|}{ جدول 1 - عناصر ماتريس درهمر يختكح } \\
\hline--- & Positive & Negative \\
\hline Positive & صحيح مثبت (TP) & اشتباه مثبت(FN) \\
\hline Negative & اشتباه مثبت(FP) & صحيح منفى (TN) \\
\hline
\end{tabular}

Accuracy $=\frac{T N+T P}{T N+F N+T P+F P}$

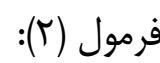

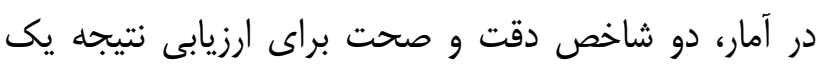

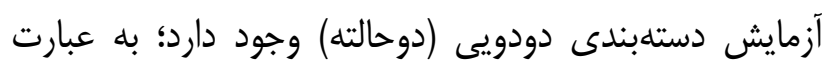

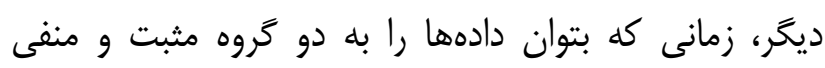

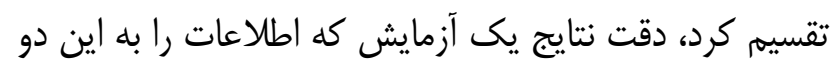

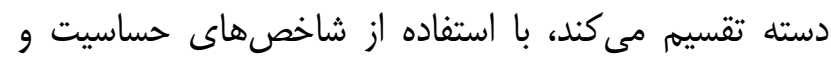

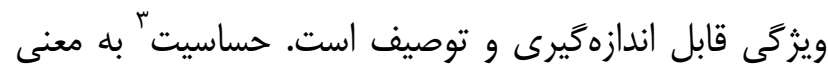

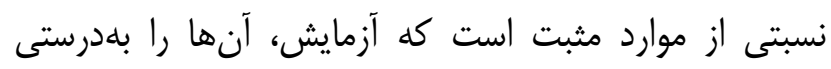

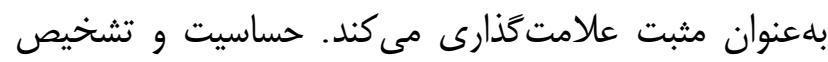

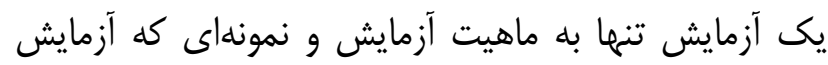

$$
o(x)_{j}=\frac{e^{x_{i}}}{\sum_{n=1}^{N} e^{x_{n}}} \text { for } \quad J=1 \ldots . . N
$$

با در نظر كرفتن لايه Flatten خروجى، لايههاى كانولوشن

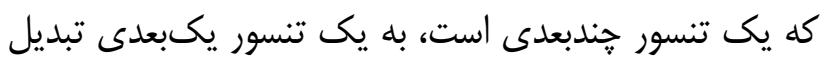

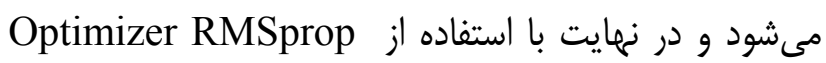

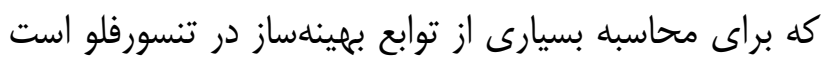

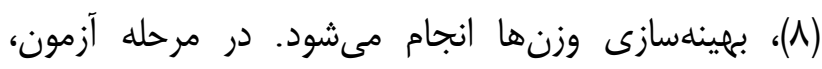
تصاويرى كه تداخلى با دادههاى آموزشى ندارند، بهعنوان

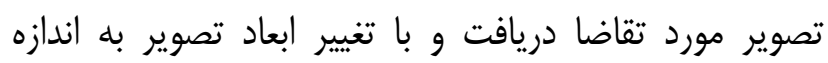

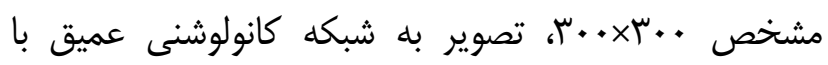

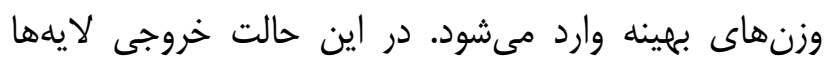

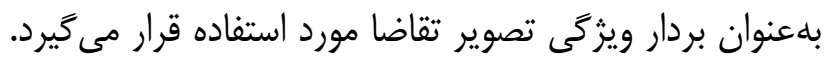

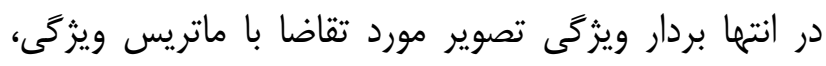

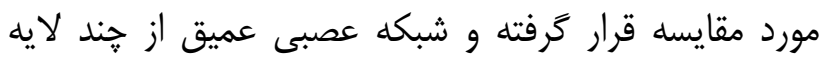
براى درى بخشهايى از دادهها استفاده مى كند؛ اما براى

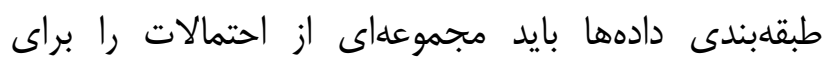
تصميم گيرى نهايى داشته باشيه. Softmax يك تابع شناخته شده است كه مقادير احتمالات را در يك محدوده استاندارد (صفر تا () نرماليزه مى كند.

يايحًاه داده:

مجموعه داده مورد استفاده در اين يزوهش، از • V تصوير

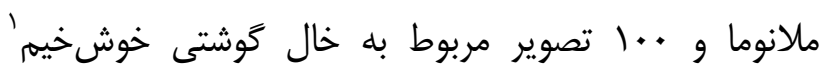

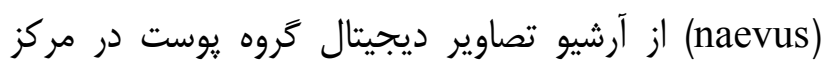

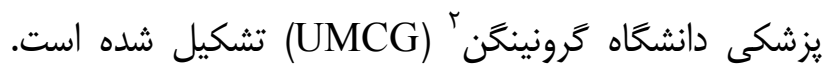

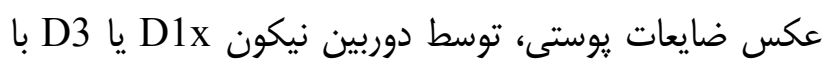

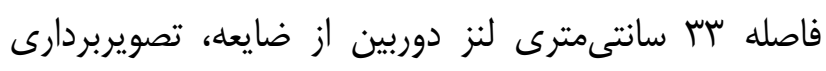

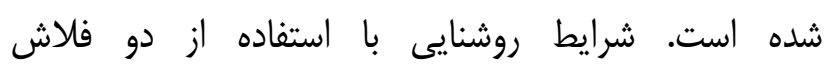
600

1 Benign
2 Groningen 
در آن استفاده مىشود، بستخى دارد. با اين حال، فقط با ارسال مى گردد كه اين شبكه در طى ..1 تكرار، آموزش

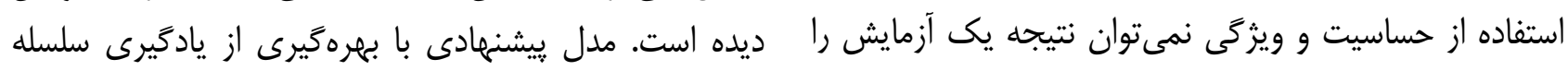

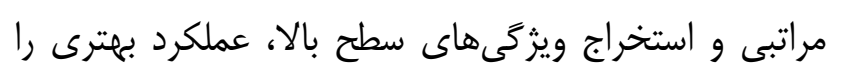
تعبير كرد.

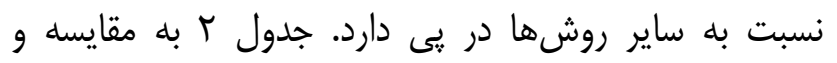

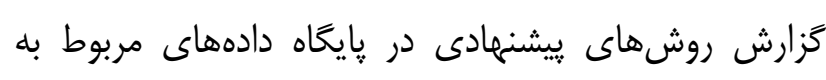

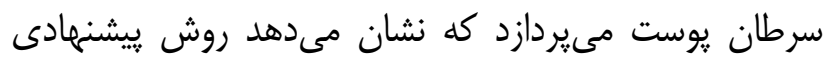

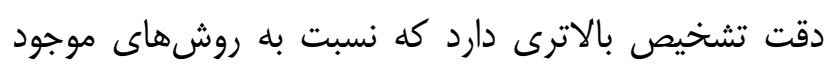

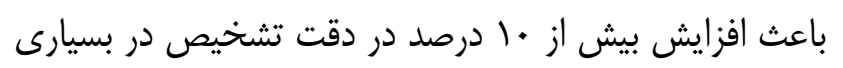
از موارد گرديده است.

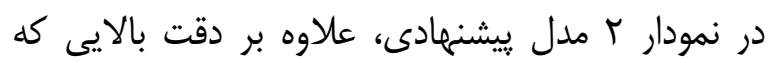

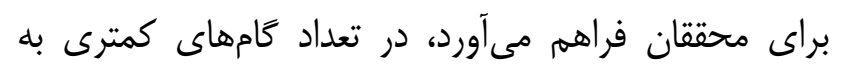

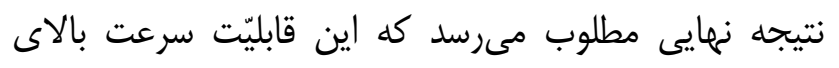
آموزش و تست دادهها را نشان مىدهد.

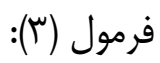
sensitivity $(\operatorname{Re}$ call $)=\frac{T P}{T P+F P}$

معيار خطاى طبقهندى دقيقاُ برعكس معيار دقت دستهبندى

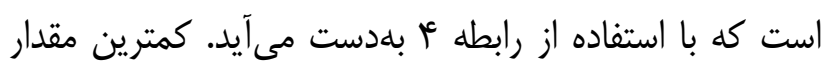

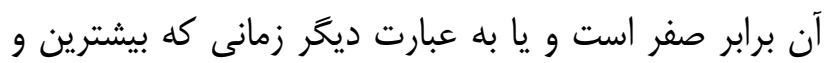

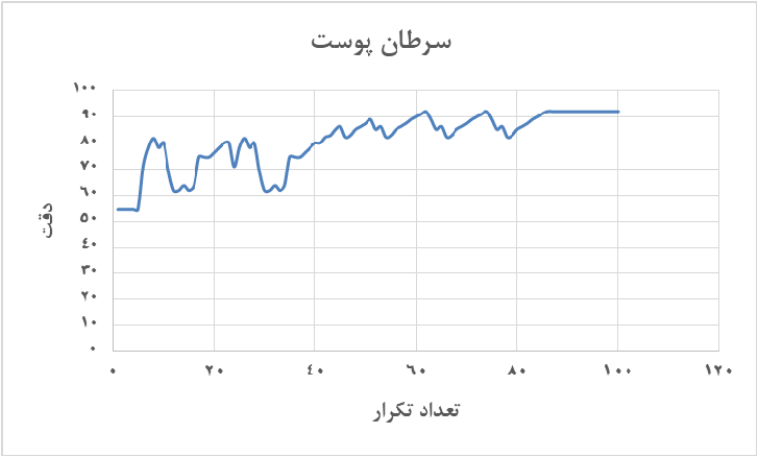

نمودار r- نمودار سير همَّرايى دقت تشخيص در سرطان يوست
Error Rate $=\frac{F N+F P}{T N+F N+T P+F P}$

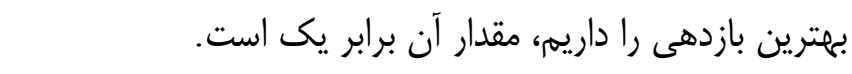 فرمول (ז)

يافته ها

ابزار يادگيرى عميق براى شناسايى ويزگى هاى كليدى از

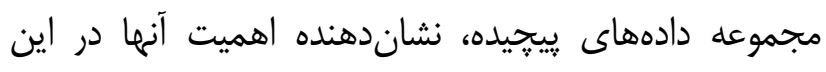

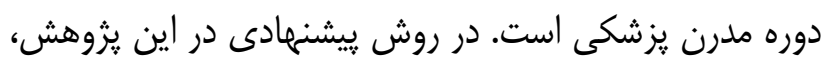

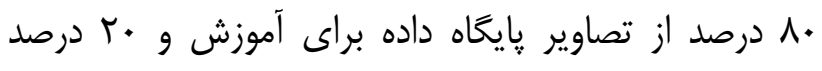

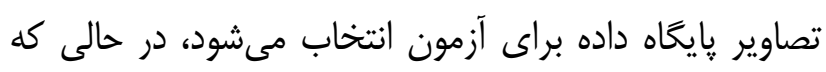

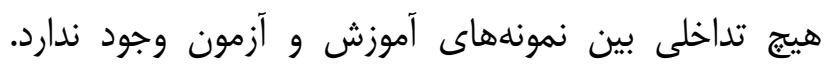

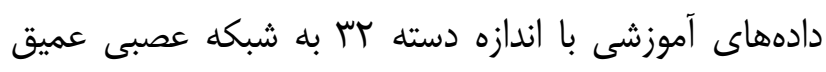

\section{جدول r- مقايسه نتايج بيشنهادى با ساير روشها در سرطان يوست}

\begin{tabular}{|c|c|c|c|c|}
\hline Error Rate(\%) & Recall(\%) & Spe (\%) & Acc (\%) & 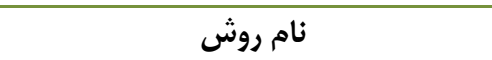 \\
\hline$I T / V \Lambda$ & v. & $9 \Delta / \wedge \mu$ & NV/TT & FNN (II) \\
\hline 1/19 & ת & 90 & $91 / 11$ & Neural Network Ensembel Model $(I r)$ \\
\hline r. & - & - & 9. & VGG-19 VGG-16 \\
\hline 11 & $V / q V$ & $q \vee / \Delta$. & 19 & الخوريتم k همسايه نزديكتر \\
\hline$I T / T r$ & $V \Delta$ & $9 \Delta / \wedge \mu$ & $\Lambda V / V \Lambda$ & Adaboost \\
\hline $\mathrm{IV} / \mathrm{q}$ & - & - & $\Lambda \Gamma / 1$ & MED-NOD (Iו) \\
\hline$I T / T r$ & Va & $q 4 / 1 V$ & $\Lambda \mathrm{V} / \mathrm{\wedge} \Lambda$ & $\left.\operatorname{RBF} \operatorname{SVM}(1)^{4}\right)$ \\
\hline $\mathrm{V} / \mathrm{q}$ & १v & $q \varepsilon / \pi$ & $9 \% / 1$ & روش ييشنهادى \\
\hline
\end{tabular}


تصوير ملانوم و +.1 تصوير خال گوشتى بلطور خودكار از تصاوير ديجيتال غيرتراكمى استخراج شد و توصيفگرهاى

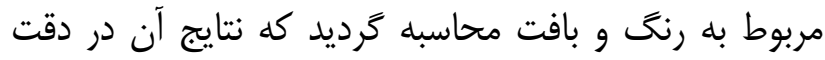

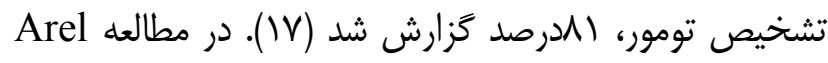

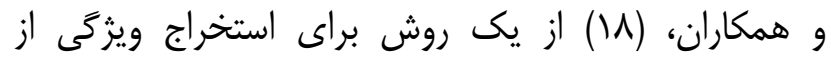

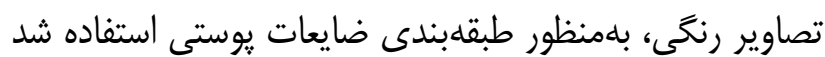

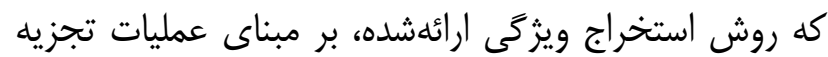

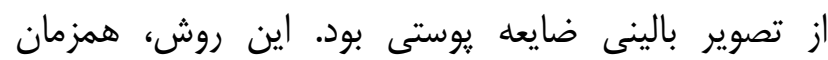
ويثگىهاى مكانى و طيفى تصوير را مورد بررسى قرار

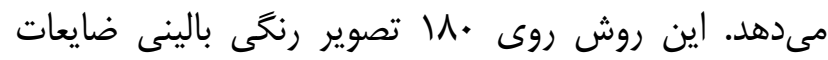

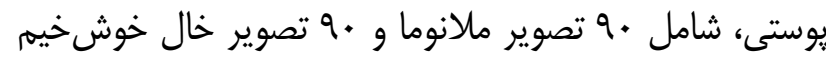

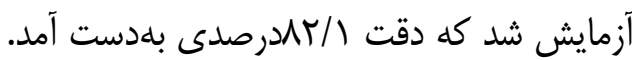

\section{نتيجه كيرى}

در اين يزوهش بلهمنظور تشخيص و طبقلهبندى سرطان

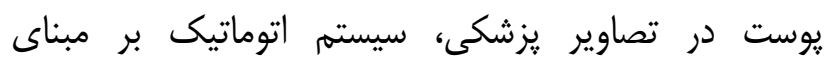

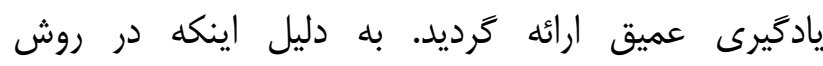

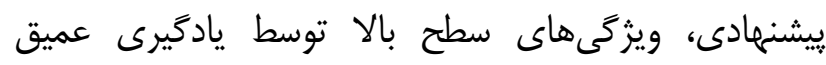

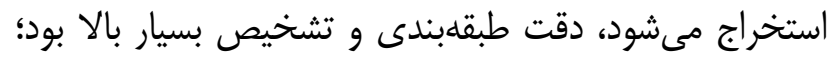

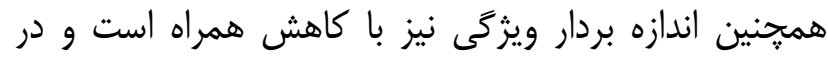

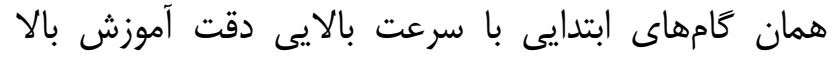

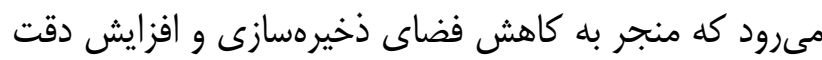

$$
\text { و سرعت مى مَردد. }
$$

\section{تقدير و تشكر}

اين مقاله حاصل بخشى از پايانامه كارشناسى ارشد

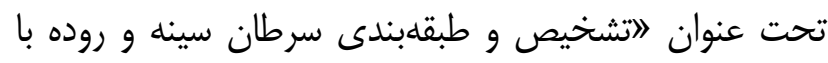
استفاده از يادگيرى عميق" مىباشد. در يايان نويسندكان اين

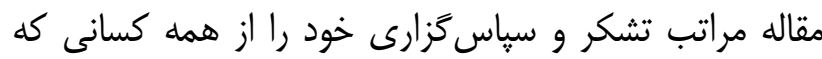
آنها را در انجام اين يزوهش يارى نمودند، اعلام مى دارند.
يادگيرى عميق بلهورت گسترده در زمينههاى گوناگونى از بينايى ماشين همانند: طبقهبندى تصاوير، تشخيص اشيا، قطعلبندى معنايى و بازيابى تصوير و برآورد حالت بدن انسان كه فعاليتهاى كليدى براى درى تصوير مىباشند، مورد

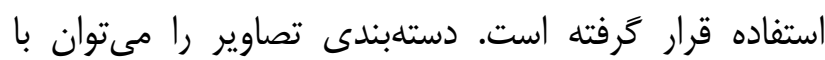

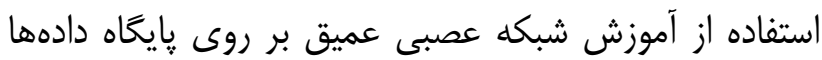

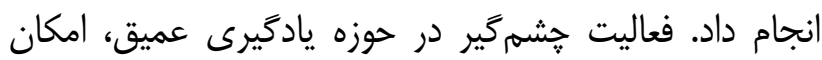

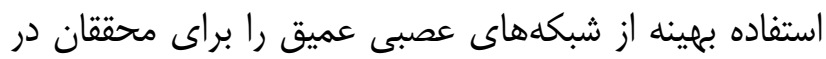

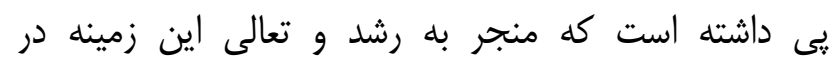
حوزههاى متفاوت علم مهندسى شده است. مطالعات قابل توجهى در مورد مسئله تشخيص خونمات مودكار

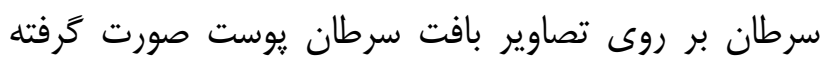

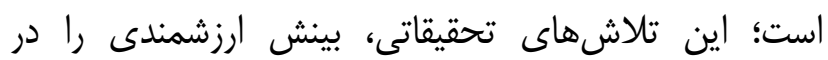

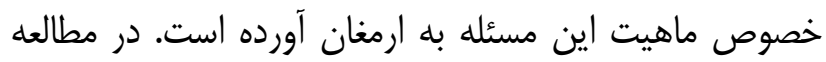
Moussa

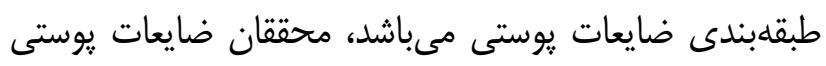

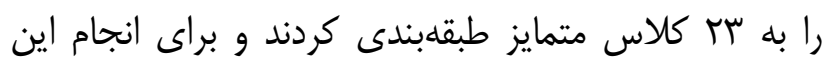

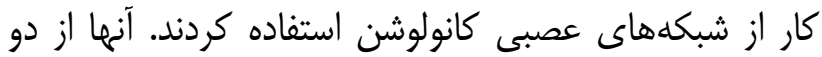

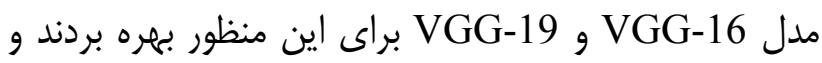
در نهايت به دقت • عدرصدى براى طبقلبندى كلاسهاى لای تعريفشده دست يِيدا كردند (1ه). براى شناسايى ملانوما نيز بلطور خاص تحقيقات متعددى صورت گرفته است. در مطالعه Giotis و همكاران، با استفاده از ويزگى هاى هندسى ملانوما و بهرهگيرى از

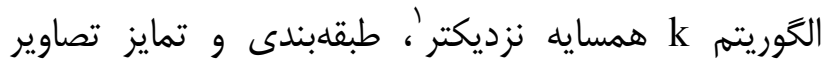

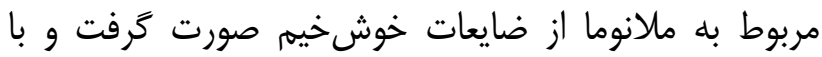
وجود مجموعه دادهاى محدود در اين يزوهش، دقت

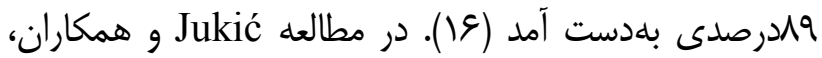

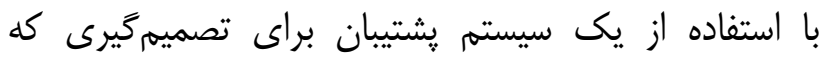

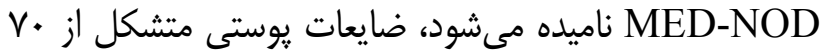




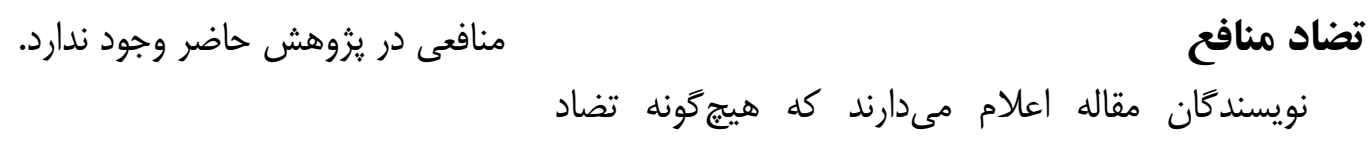

منابع:

1- Shimizu K, Iyatomi H, Celebi ME, Norton KA, Tanaka M. Four-class classification of skin lesions with task decomposition strategy. IEEE Trans Biomed Eng. 2015; 62(1):274-83.

2- Nasr-Esfahani E, Samavi S, Karimi N, Soroushmehr SMR, Jafari MH, Ward K, et al. Melanoma detection by analysis of clinical images using convolutional neural network. 38th Annual International Conference of the IEEE Engineering in Medicine and Biology Society (EMBC); 2016 Aug 16-20; Orlando, FL, USA. IEEE; 2016.

3- American Cancer Society. Cancer Facts \& Figures 2016. Atlanta, GA, USA: American Cancer Society; 2016.

4- Gautam D, Ahmed M. Melanoma detection and classification using SVM based decision support system. Annual IEEE India Conference (INDICON); 2015 Dec 17-20; New Delhi, India. IEEE; 2016.

5- Jain S, Jagtap V, Pise N. Computer aided melanoma skin cancer detection using image processing. Procedia Comput Sci. $2015 ;$ 48: 735-40

6- Garnavi R, Aldeen M, Bailey J. Computer-aided diagnosis of melanoma using border-and wavelet-based texture analysis. IEEE Trans Inf Technol Biomed. 2012; 16(6): 1239-52.

7- Sheha MA, Mabrouk MS, Sharawy A. Automatic detection of melanoma skin cancer using texture analysis. Int J Comput Appl. 2012; 42(20): 22-6.

8- Lo SC, Lou SL, Lin JS, Freedman MT, Chien MV, Mun SK. Artificial convolution neural network techniques and applications for lung nodule detection. IEEE Trans Med Imaging. 1995; 14(4): 711-8.

9- Ji S, Xu W, Yang M, Yu K. 3D convolutional neural networks for human action recognition. IEEE Trans Pattern Anal Mach Intell. 2013; 35(1): 221-31.

10- Litjens G, Kooi T, Bejnordi BE, Adiyoso Setio AA, Ciompi F, Ghafoorian M, et al. A survey on deep learning in medical image analysis. Med Image Anal. 2017; 42: 60-88.

11- Rajesh A. Classification of malignant melanoma and Benign Skin Lesion by using back propagation neural network and ABCD rule. 2017 IEEE International Conference on Electrical, Instrumentation and Communication Engineering (ICEICE); 2017 Apr 27-28; Karur, India. IEEE; 2017.

12- Xie F, Fan H, Li Y, Jiang Z, Meng R, Bovik A. Melanoma classification on dermoscopy images using a neural network ensemble model. IEEE Trans Med Imaging. 2017; 36(3): 849-58.

13- Premaladha J, Ravichandran KS. Novel approaches for diagnosing melanoma skin lesions through supervised and deep learning algorithms. J Med Syst. 2016; 40(4): 96.

14- Barata C, Ruela M, Francisco M, Mendonça T, Marques JS. Two systems for the detection of melanomas in dermoscopy images using texture and color features. IEEE Syst J. 2014; 8(3): 965-79.

15- Moussa R, Gerges F, Salem C, Akiki R, Falou O, Azar D. Computer-aided detection of Melanoma using geometric features. InBiomedical Engineering (MECBME). 3rd Middle East Conference on Biomedical Engineering (MECBME); 2016 Oct 6-7; Beirut, Lebanon. IEEE; 2016.

16- Giotis I, Molders N, Land S, Biehl M, Jonkman MF, Petkov N. MED-NODE: A computer-assisted melanoma diagnosis system using non-dermoscopic images. Expert Syst Appl. 2015; 42(19): 6578-85.

17- Jukić A, Kopriva I, Cichocki A. Noninvasive diagnosis of melanoma with tensor decomposition-based feature extraction from clinical color image. Biomed Signal Process Control. 2013; 8(6): 755-63.

18- Arel I, Rose DC, Karnowski TP. Deep machine learning-a new frontier in artificial intelligence research [research frontier]. IEEE Comput Intell Mag. 2010; 5(4): 13-8. 